Revista de Economia Política, vol. 27, no 4 (108), pp. 507-524 outubro-dezembro/2007

\title{
Por que novo-desenvolvimentismo?
}

\author{
JOÃO SICSÚ \\ LUIZ FERNANDO DE PAULA \\ REN AUT MICHEL*
}

Why new-developementalism? This paper develops some general guidelines that should take part of a new view of development to Brazil, in opposition to the neoliberal project. This alternative, that is called "new developmentalism", should include sustained economic growth with social equity.

K ey-words: developmentalism, State, strategy of development.

JEL Classification: E24, 011, P41.

A mais importante A genda do Estado não está relacionada às atividades que os indivíduos particularmente já realizam, mas às funções que estão fora do âmbito individual, àquelas decisões que ninguém adota se o Estado não o faz. Para o governo, o mais importante não é fazer coisas que os indivíduos já estão fazendo, e fazêllas um pouco melhor ou um pouco pior, mas fazer aquelas coisas que atualmente deixam de ser feitas.

J. M. Keynes, "O fim do laissez-faire", 1926

\footnotetext{
* O s autores são, respectivamente: professor do Instituto de Economia da Universidade Federal do Rio de Janeiro (IE/UFRJ) e pesquisador do CN Pq. E-mail: jsicsu@terra.com.br; professor da Faculdade de Ciências Econômicas da Universidade do Estado do Rio de J aneiro (FCE/UERJ) e pesquisador do CN Pq. E-mail: luizfpaula@terra.com.br e webpage: http://paginas.terra.com.br/educacao/luizfpaula; e professor da Universidade Candido M endes (UCAM ). E-mail: rmichel@candidomendes.edu.br. Este artigo é uma versão ampliada e bastante modificada da Introdução feita pelos autores ao livro "N ovo-D esenvolvimentismo: um projeto nacional de crescimento com equidade social", (ver Sicsú, Paula e M ichel, 2005). A gradecemos a Luiz Carlos Bresser-Pereira e M ichael Fritsche pelas discussões e sugestões feitas sobre 0 assunto tratado no artigo, assim como um parecerista anônimo, isentando-os, evidentemente, de erros e omissões remanescentes. Submetido: Fevereiro 2006; aceito: O utubro 2006.
} 


\section{INTRODUÇÃO}

$\mathrm{N}$ este artigo exploramos algumas linhas gerais que podem compor uma alternativa de política de desenvolvimento que compatibilize crescimento econômico com eqüidade social, buscando estimular o debate em torno da constituição de um programa alternativo ao projeto neoliberal. Inicialmente pensou-se simplesmente em usar - como ponto de partida da discussão - a expressão D esenvolvimentismo - em oposição ao puro monetarismo neoliberal, há muito em voga. Todavia, esse rótulo parece não ser o mais adequado para abranger uma nova realidade, em diversos aspectos, mais complexa. Afinal, trata-se de uma realidade diversa e em certo sentido muito mais indecifrável que aquela dos anos 1950, quando a industrialização esteve baseada no modelo de substituição de importações, que tinha como pilares básicos um protecionismo generalizado do mercado interno e uma ampla intervenção governamental, inclusive através de empresas estatais atuando em setores de infra-estrutura e de produção de insumos básicos. ${ }^{1} \mathrm{H}$ oje, contudo, não faz mais sentido o Estado brasileiro atuar diretamente em setores como indústria siderúrgica ou petroquímica; ademais, as disputas comerciais internacionais se tornaram muito mais complexas e acirradas e os sistemas financeiros nacionais de diversos países se integraram - globalizaram-se. O s tempos atuais são outros e exigem, portanto, uma nova estratégia desenvolvimentista.

Bresser-Pereira publicou um instigante artigo, na Folha de São Paulo (19/09/2004), intitulado "N ovo-desenvolvimentismo" - com o qual temos muitos pontos concordantes - , e que explora basicamente linhas gerais macroeconômicas relacionadas a esse conceito. ${ }^{2} \mathrm{~A}$ lém de tópicos macroeconômicos adicionais, queremos explorar nesse artigo algumas outras questões que são fundamentais em uma política de desenvolvimento, principalmente, a relação entre as esferas pública-privada, econômica-social e nacional-internacional.

0 novo-desenvolvimentismo tem diversas origens teórica-analíticas, entre as quais a visão de K eynes e de economistas keynesianos contemporâneos ${ }^{3}$ de com-

\footnotetext{
${ }^{1}$ Para uma análise das características deste modelo, ver, entre outros, Serra (1982) e Suzigan (1988).

${ }^{2}$ Em linhas gerais, Bresser-Pereira (2004a) relaciona o novo-desenvolvimentismo - enquanto estratégia nacional de desenvolvimento - aos seguintes elementos: (i) uma maior abertura da conta comercial do país, que deve ser feita de forma negociada e com reciprocidades; (ii) um novo papel do Estado, com um planejamento mais estratégico; (iii) preocupação com a estabilidade macroeconômica, incluindo não só estabilidade de preços como também equilíbrio do balanço de pagamentos e busca do pleno emprego; (iv) uma nova política macroeconômica, que permita inverter a equação perversa juros elevados e câmbio apreciado; (v) não aceitar a estratégia de crescimento com poupança externa, visando alternativamente financiar o desenvolvimento com recursos próprios de cada nação. O conceito de "novo-desenvolvimentismo", contudo, havia sido desenvolvido anteriormente em Bresser-Pereira (2003, cap. 20).

${ }^{3}$ Entre eles, pode-se destacar Paul Davidson e J oseph Stiglitz. Ver, entre outros trabalhos, Davidson (1994) e Stiglitz (1999).
} 
plementaridade entre Estado e mercado e a visão cepalina neo-estruturalista que, tomando como ponto de partida que a industrialização latino-americana não foi suficiente para resolver os problemas de desigualdades sociais na região, defende a adoção de uma estratégia de "transformação produtiva com eqüidade social" que permita compatibilizar um crescimento econômico sustentável com uma meIhor distribuição de renda4.

$\mathrm{N}$ a nossa concepção, a alternativa novo-desenvolvimentista não objetiva pavimentar a estrada que poderia levar o Brasil a ter uma economia centralizada, com um Estado forte e um mercado fraco. Esta alternativa também não objetivaria construir o caminho para a direção oposta, em que unicamente o mercado comandaria a economia, com um Estado fraco. Uma visão novo-desenvolvimentista rejeitaria essas duas possibilidades extremas. Contudo, entre esses dois extremos existem ainda muitas opções. Avaliamos que a melhor delas é aquela em que seriam constituídos um Estado forte que estimula o florescimento de um mercado forte. N ossas teses - que serão analisadas no que segue - são as seguintes: (i) não haverá mercado forte sem um Estado forte; (ii) não haverá crescimento sustentado a taxas el evadas sem o fortalecimento dessas duas instituições (Estado e mercado) e sem a implementação de políticas macroeconômicas adequadas; (iii) mercado e Estado fortes somente serão construídos por uma estratégia nacional de desenvolvimento; e (iv) não é possível atingir o objetivo da redução da desigualdade social sem crescimento a taxas elevadas econtinuadas. D eve-se ressalvar, contudo, que este artigo objetiva tão-somente discutir o que entendemos por "novo-desenvolvimentismo" e traçar linhas gerais de conduta do Estado e políticas econômicas compatíveis com esta visão, não tendo a pretensão de discutir uma "estratégia de desenvolvimento" stricto sensu.

\section{ESTADO E MERCADOSFORTES}

No âmbito da teoria econômica, a discussão inicial sobre o papel do Estado foi, em certa medida, abordada de forma sistematizada e ampla por A dam Smith em sua clássica obra "A Riqueza das N ações", 5 de 1776. N ela, Smith tentou mostrar que a economia tem uma lógica própria: os agentes econômicos, buscando satisfazer seus interesses individuais, espontaneamente, organizam a economia de forma eficiente. Tal abordagem ficou conhecida pela imagem metafórica da mão invisível. Esta seria representada pelo conjunto de forças individuais operando na mais pura concorrência para realizar as necessidades de vendas (oferta) e de compras (demanda) - portanto, satisfazendo em sua plenitude os desejos

\footnotetext{
${ }^{4}$ A propósito, ver a publicação Transformacion Productiva com Equidad, Santiago, da Cepal (Cepal, 1990). Ver, também, Bielschowsky (2000).

${ }^{5}$ Smith (1983).
} 
individuais. Os mais produtivos venderiam maiores quantidades a preços menores e, portanto, suas capacidades de comprar e acumular riquezas seriam também maiores, mas elas seriam apenas uma recompensa por suas habilidades individuais. Portanto, os mais produtivos tenderiam a enriquecer, enquanto os menos eficientes tenderiam a sofrer e a desaparecer, em uma espécie de seleção natural dos mais aptos feita pelo mercado.

$\mathrm{N}$ a visão smithiana, o Estado seria um corpo estranho, com capacidade de interferir e atrapalhar a realização de impulsos, necessidades e recompensas individuais naturais. 0 Estado, se utilizando de regras e/ou políticas governamentais, segundo a visão dos conservadores liberais dos dias de hoje, unicamente seria capaz de mel horar a vida de uns em detrimento da qualidade de vida de outros. Por exemplo, a concessão de subsídios seria necessariamente uma transferência deformadora, um privilégio, que retira parte da remuneração considerada justa dos mais habilidosos para recompensar indivíduos e/ou empresas não-merecedoras, porque seriam inábeis.

M odernamente, a teoria monetarista neoliberal desenvolveu todo o seu arcabouço com base na abordagem da mão invisível do mercado. ${ }^{6}$ Esta teoria concluiu que a interferência pública na economia gera, além dos privilégios individuais já mencionados, os mais graves problemas macroeconômicos, como, por exemplo, a inflação e até mesmo crises cambiais. 0 governo é considerado sempre irresponsável e gastador - portanto, gerador de inflação. ${ }^{7}$ Por exemplo, uma política de governo que tenta formar reservas internacionais para defender a moeda do país contra ataques especulativos amplia a liquidez da economia, gerando inflação. Se o governo enxuga a liquidez vendendo títulos públicos, ampliaria a relação dívida/PIB, estimulando a fuga de capitais, o que poderia fazer emergir uma crise cambial. ${ }^{8}$

Segundo a visão monetarista neoliberal, o câmbio e os fluxos de capitais devem estar livres. Se movimentos bruscos de capitais ocorrem, provocando flutuações não desejáveis na taxa de câmbio, é porque foi implementada al guma política governamental (de gastos públicos ou de redução de juros) considerada indevida pelo mercado (leia-se financeiro), que prontamente tenta vetá-la. Assim, a discipli-

\footnotetext{
${ }^{6} \mathrm{~A}$ concepção moderna do liberalismo está originariamente desenvolvida em H ayek (1984).

${ }^{7}$ Alguns pressupostos desta concepção são: (i) dicotomia entre lado monetário e real da economia ("dicotomia clássica" ); (ii) neutralidade da moeda a longo prazo; (iii) ineficácia de políticas econômicas ativistas; (iv) as autoridades monetárias têm intrinsecamente um viés inflacionário ("inflationary bias"). Ver, a respeito, Snowdon et al (1994, cap. 1).

${ }^{8} \mathrm{~A}$ fração mencionada seria objeto de observação atenta por parte dos credores porque indicaria a possibilidade do governo honrar seus compromissos. Se esta relação se torna ascendente com características explosivas, os credores venderiam os títulos que estavam carregando e se dirigiriam para países mais seguros. A dívida pública computada na relação dívida/PIB é a dívida líquida, de forma que a simples aquisição de reservas não faz aumentar esta relação; tal relação tenderia a aumentar no caso de emissão de títulos porque é necessário que juros sejam pagos para que títulos sejam demandados pelo setor privado. São os juros pagos que elevariam a relação dívida/PIB.
} 
na do mercado impõe aos governos (ditos "irresponsáveis") a adoção de políticas econômicas consideradas "sólidas" e "corretas". ${ }^{9}$ G overnos são julgados e condenados ou absolvidos pelas ações dos investidores financeiros internacionais (dito "racionais"). A receita convencional consiste em ter um Estado mínimo e fraco e amarrar as mãos do governo para que a mão invisível possa operar livremente.

Já a concepção de mercados regulados e da necessidade de complementaridade entre Estado e mercado foi desenvolvida, entre outros por Keynes e Polanyi, emais recentemente por outros economistas, como Stiglitz. Para Polanyi (1980), em livro escrito originalmente em 1944, mercados modernos são instituições socialmente constituídas, isto é, que devem ser organizados e regulados pelos Estados nacionais, tanto no âmbito nacional quanto no âmbito internacional. Stiglitz (1999) sustenta que o Estado deve agir como complemento dos mercados, ao contrário da visão de Estado minimalista, não-intervencionista, defendida pelo Consenso de Washington. ${ }^{10}$ Para ele, o Estado deve adotar ações que façam os mercados funcionarem melhor, procurando corrigir as falhas no funcionamento destes. Destaca, além de sua importância na regulação apropriada, seu papel na proteção social, no sistema previdenciário e na promoção da educação pública.

A defesa mais elaborada do papel do Estado na economia talvez continue a ser aquela feita por Keynes. ${ }^{11}$ Ao criticar a visão liberal, segundo o qual o mercado auto-regulado é capaz de fazer uma alocação ótima dos recursos disponíveis e o "darwinismo" econômico implícito nesta visão ("o mercado seleciona os mais fortes", de acordo com sua metáfora das girafas ${ }^{12}$ ), Keynes defendia que a soma

\footnotetext{
${ }^{9}$ Esta visão está desenvolvida, por exemplo, em Dornbusch (1998) e Fischer (1998).

${ }^{10} \mathrm{O}$ Consenso de Washington foi concebido originalmente por John Williamson (1990), economista do Banco M undial, que sugeriu um conjunto de proposições que rapidamente se tornou no denominador comum das proposições e aconselhamento político das instituições baseadas em Washington (Banco M undial e FM I) para os países latino-americanos, e mesmo para outros países em desenvolvimento. Tais proposições objetivam estimular o crescimento econômico através de um conjunto de políticas e reformas de natureza liberalizante, que visavam a disciplina macroeconômica (entendida como estabilidade de preços), abertura comercial e políticas microeconômicas de mercado. A recomendação de abertura da conta de capital, que não constava das proposições originais de Williamson, foi acrescentada ao receituário pelas instituições multilaterais. Assim, o chamado "Consenso de Washington" foi a base das reformas liberalizantes que, em maior ou menor grau, foram aplicadas em vários países da A mérica Latina, incluindo Argentina, Brasil e M éxico, ao longo da década de 1990.

${ }^{11}$ Ver, em particular, Keynes (1984, 1986).

${ }^{12}$ Keynes (1984, p. 116) considerava um erro “ (... ) supor um estado de coisas no qual a distribuição ideal dos recursos produtivos pode ser conseguida através de indivíduos que agem de maneira independente, pelo método de ensaio e erro, de tal maneira que os indivíduos que se movimentam na direção correta destruirão, pela competição, aqueles que se movimentam na direção errada. Isto implica não haver perdão ou proteção para os que empatam o seu capital ou o seu trabalho na direção errada. Este é um método para elevar ao topo os negociantes melhor sucedidos, mediante uma luta cruel pela sobrevivência, que seleciona os mais eficientes pela falência dos menos eficientes. $N$ ão se leva em conta o custo da luta, mas apenas o resultado final, que supõem serem permanentes. Como o objetivo é colher as folhas dos galhos mais altos, a maneira mais provável de alcançá-lo é deixar que as girafas de pescoços mais longos façam morrer à mingua as de pescoços mais curtos".
} 
dos interesses particulares nem sempre coincide com o interesse coletivo, ou seja, 0 auto-interesse nem sempre atua a favor do interesse público, pois o mercado, além de poder ser falho na alocação dos recursos e na promoção do pleno emprego, exclui os mais fracos (empresas e trabalhadores). A intervenção do Estado seria necessária em função da incapacidade de auto-regulação do sistema.

Para K eynes deveria haver uma complementaridade entre o Estado e o mercado: quase todas as atividades econômicas do capitalismo exigem o estímulo ao ganho individual, cabendo ao auto-interesse a determinação do que será produzido e em que proporção se associarão os fatores de produção para realizar tal tarefa. Contudo, em determinadas condições o livre jogo das forças do mercado precisa ser refreada ou mesmo guiado. Portanto, a principal ação do economista e do policy-maker é fazer a distinção entre a Agenda do Governo e a não-agenda: "a mais importante $A$ genda do Estado não diz respeito às atividades que os indivíduos particularmente já realizam, mas às funções que estão fora do âmbito individual, àquelas decisões que ninguém adota se o Estado não o faz. Para o governo, o mais importante não é fazer coisas que os indivíduos já estão fazendo (...), mas fazer aquelas coisas que atualmente deixam de ser feitas" (Keynes, 1984, p. 123). Keynes avaliava que o Estado seria capaz de arbitrar e estimular a concorrência e, além disso, de influir de forma decisiva sobre as variáveis econômicas mais relevantes, como o desemprego, a inflação e a distribuição de renda e da riqueza.

\section{A ALTERN ATIVA NOVO-DESEN VOLVIM ENTISTA}

A alternativa novo-desenvolvimentista aos males do capitalismo é a constituição de um Estado capaz de regular a economia - que deve ser constituída por um mercado forte e um sistema financeiro funcional - isto é, que seja voltado para o financiamento da atividade produtiva e não para a atividade especulativa. ${ }^{13}$ Para tanto, é necessário não só buscar formas inteligentes de ação estatal, complementares à ação privada, como também proporcionar condições para que - Estado possa desempenhar de forma mais eficaz sua ação - para o que pode ser necessário uma "reforma da gestão pública". Trata-se de adotar uma forma de gestão que aproxime as práticas dos gerentes públicos às dos privados, tornando-os ao mesmo tempo mais autônomos e responsáveis perante a sociedade. ${ }^{14}$

\footnotetext{
${ }^{13}$ Segundo K eynes (1986), a atividade especulativa tem um impacto ambíguo sobre os mercados financeiros, porque, embora a liquidez dos mercados financeiros freqüentemente facilite, às vezes impede o curso de um novo investimento. Keynes e pós-keynesianos sustentam que há fortes conexões entre os setores financeiro e real da economia. U ma das conexões é o impacto da atividade especulativa sobre a atividade produtiva, especialmente sobre o investimento. É bem conhecida a passagem da Teoria Geral em que Keynes (1986, p. 159) diz que “a posição é séria quando o empreendimento se torna uma bolha sobre um redemoinho da especulação. Q uando o desenvolvimento de um país se torna um subproduto das atividades de um cassino, o trabalho normalmente é mal feito" .

${ }^{14} \mathrm{Ver}$, a respeito, Bresser-Pereira (2004b).
} 
Tal reforma requer não somente uma maior profissionalização da gestão pública como também um certo grau de descentralização do Estado, com a transferência de determinadas funções específicas do Estado a agências (semi)autônomas e a transferência de serviços sociais e científicos a organizações de serviço públicas, semi ou não-estatais. $\mathrm{N}$ ote-se, contudo, que isto não significa que as decisões mais importantes relativas às políticas públicas a serem implementadas devam ser igualmente descentralizadas, pois cabe às esferas governamentais, el eitas democraticamente, a definição destas. ${ }^{15}$

$\mathrm{N}$ a visão novo-desenvolvimentista, a concorrência é necessária porque estimula a inovação por parte dos empresários que tentam maximizar o lucro, o que torna o capitalismo dinâmico e revolucionário, e estabelece remunerações e riquezas diferenciadas aos indivíduos de acordo com suas habilidades. M as devem existir regras reguladoras para que não se tenha como resultado da concorrência o óbvio: perdem os grandes porque numa briga sempre se incorre em custos e desaparecem os menores simplesmente porque são menores. Como disse K eynes, se levarmos a sério o bem-estar das girafas, não devemos menosprezar o sofrimento daquelas de pescoços mais curtos, que morrem de fome, ou as folhas doces que caem no chão e são pisadas na luta, ou a superalimentação das de pescoços compridos... ${ }^{16}$

Um Estado forte pode regular a concorrência - o resultado deve ser a constituição de um mercado forte onde predomina a busca pela redução de custos e de preços, pela melhoria da qualidade dos serviços e produtos e onde, conseqüentemente, haverá um reduzido desemprego, já que os menores e/ou menos eficientes também poderiam trabalhar, produzir, enfim, fazer parte do mercado. 0 resultado da concorrência desregulada é a eliminação dos pequenos e médios (o que é injusto, causa desemprego e falências empresariais), o aumento de preços e a redução da qualidade dos produtos e serviços graças à conquista de uma situação pura de oligopólio ou, mesmo, monopólio.

$\mathrm{N}$ a concepção novo-desenvolvimentista, o Estado deve ser forte para permitir ao governo a implementação de políticas macroeconômicas defensivas ou expansionistas. Políticas de caráter defensivo são, por exemplo, aquelas que reduzem a sensibilidade do país a crises cambiais; e, políticas expansionistas referem-se àquelas medidas de promoção do pleno emprego, sobretudo em contextos recessivos. Políticas industrial e de comércio exterior - usadas de forma inteligente e

\footnotetext{
${ }^{15} \mathrm{~N}$ este sentido, diz Keynes (1984, p. 121, itálicos acrescentados), "sugiro, portanto, que o progresso reside no desenvolvimento e reconhecimento de entidades semi-autonômas dentro do Estado - entidades cujo critério de ação em seus próprios campos seja unicamente o bem público, tal como elas o compreendem; e de cujas deliberações estejam excluídos os motivos de vantagens particulares, embora ainda possa ser preciso deixar-Ihes algum lugar até que se amplie o âmbito de altruísmo dos homens, para o proveito isolado de grupos, classes ou congregações específicas - , entidades que, no curso habitual da vida social, são basicamente autônomas dentro das limitações que lhes são prescritas, sendo porém sujeitas, em última instância, à soberania da democracia expressa através do Parlamento".

${ }^{16}$ Keynes (1984, p. 118).
} 
criativa - devem e podem ser utilizadas para estimular a competitividade da indústria e melhorar a inserção do país no comércio internacional. 0 Estado deve, ademais, possuir um sistema tributário progressivo, para reduzir as desigualdades de renda e de riqueza que são exageradas. As desigualdades menores devem permanecer. A final, os indivíduos e as empresas têm capacidades diferenciadas.

Uma economia de mercado desregulada com um Estado fraco e com um governo paralisado não é capaz de ampliar a propriedade do capital, de garantir condições para um ambiente de uma concorrência sadia, de reduzir o desemprego ou de eliminar as desigualdades exageradas de renda e riqueza. Esta é uma lição da história, visível. Só a fé cega faz com que muitos acreditem no contrário. E chegam a acreditar até mesmo naquilo que não podem ver: a existência de uma mão invisível do mercado.

\section{VELHO E NOVO-DESEN VOLVIMENTISM O}

A estratégia desenvolvimentista dos anos 1950 na A mérica Latina foi fortemente influenciada pelo chamado "pensamento cepalino", desenvolvido a partir dos trabalhos de R aul Prebisch e C elso Furtado, que desenvolveu "uma proposição política para países subdesenvolvidos, ou seja, a de industrializar, como meio de superar a pobreza ou de reduzir a diferença entre eles e os países ricos, e de atingir independência política e econômica através de um crescimento econômico auto-sustentado" ${ }^{17} \mathrm{~A}$ Cepal, ao efetuar uma crítica à doutrina dominante do livre comércio, a partir da análise da deterioração dos termos de troca e do desenvolvimento desigual na propagação do progresso técnico, ${ }^{18}$ defendia que a industrialização era o único meio que os países latino-americanos dispunham para captar os frutos do progresso técnico e el evar progressivamente a qualidade de vida da população. 0 aprofundamento da industrialização, contudo, requeria a adoção de medidas públicas, em particular o planejamento estatal e o protecionismo, visando a substituição de importações.

A estratégia desenvolvimentista, que implementou a industrialização pesada no Brasil, a partir dos anos 1950, foi fortemente influenciada pelas contribuições cepalinas. $\mathrm{N}$ um certo sentido, o Brasil foi o caso mais bem sucedido de industrialização baseada na estratégia nacional-desenvolvimentista, ao lograr êxito no seu processo de industrialização pesada. 0 Estado, como planejador, sustentador fi-

\footnotetext{
${ }^{17}$ Cf. Bielschowsky (1988, p. 11).

${ }^{18} \mathrm{O}$ desenvolvimento desigual do progresso técnico decorria da existência de estruturas produtivas distintas entre 0 centro, com estruturas diferenciadas e homogêneas, e a periferia, com estruturas especializadas e duais, em que através do comércio internacional o centro não apenas conservava os incrementos de produtividade, como se apropriava de parte do progresso técnico da periferia. Textos originais de autores da Cepal (R.Prebisch, A níbal Pinto, C. Furtado, F. H. Cardoso, M. C. Tavares entre outros) foram re-publicados em Bielschowsky (2000).
} 
nanceiro dos grandes blocos de investimento e produtor direto de insumos básicos e infra-estrutura, e as empresas transnacionais, concentrando-se nos segmentos mais dinâmicos da indústria de transformação, foram os protagonistas deste processo. A empresa privada nacional teve um papel complementar, se constituindo na realidade na sócia menor do chamado "tripé econômico". ${ }^{19}$

A ausência de uma burguesia nacional forte é um dos aspectos críticos no estabelecimento de uma estratégia nacional de desenvolvimento no Brasil. ${ }^{20}$ A lém da falta de uma política estatal mais efetiva e de longo prazo que favorecesse a empresa privada nacional no processo de desenvolvimento industrial, o "protecionismo tarifário generalizado e sem tempo determinado para acabar" não estimulou o processo de aprendizagem das empresas nacionais. Isto ocorreu porque não foi acompanhado de um processo concomitante de geração de exportações e de desenvolvimento tecnológico. Em outras palavras, o processo de substituição de importações no Brasil não requereu a absorção e o desenvolvimento tecnológico, contribuindo para incutir no empresariado industrial brasileiro "uma mentalidade protecionista, que [encarava] o protecionismo com um fim e não como um meio para que, num determinado horizonte de tempo, se [implantasse] uma indústria eficiente e competitiva, voltada tanto para o mercado interno quanto para o mercado internacional" (Suzigan, 1988, p. 10, itálicos no original).

A estratégia novo-desenvolvimentista, embora tenha suas origens no "velho desenvolvimentismo", ainda que com um olhar crítico em alguns aspectos desta estratégia, busca adequar a estratégia desenvolvimentista aos novos tempos e à realidade brasileira atual. $\mathrm{N}$ ão faz mais sentido, no atual estágio de desenvolvimento produtivo brasileiro, a existência de um Estado-empresário e de um protecionismo do mercado interno nos moldes do passado. 0 novo-desenvolvimentismo, como já assinalado, não propõe a redução do Estado, mas a sua reconstrução, tornando-o mais forte, e mais capaz no plano político, regulatório e administrativo, além de financeiramente sólido. Propõe, ademais, uma estraté gia nacional de desenvolvimento que promova políticas voltadas ao progresso técnico e a introdução de novas técnicas de produção, o desenvolvimento de mecanismos nacionais de financiamento do investimento, políticas econômicas redutoras de incertezas inerentes ao mundo financeiramente globalizado e o desenvolvimento de instituições específicas adequadas ao desenvolvimento (como o desenvolvimento do capital humano através da educação pública).

\footnotetext{
${ }^{19}$ Ver, a respeito, Serra (1984, Parte I).

${ }^{20}$ Diferentemente do caso brasileiro, a estratégia nacional de desenvolvimento da Coréia do Sul buscou justamente estimular a criação de um empresariado nacional forte e competitivo.
} 
O desenvolvimento de um país é um processo idiossincrático, de certa forma não-reprodutível. Não há um único modelo a ser seguido, e sim inúmeras possibilidades ecombinações. Estudo recente feito por H ausmann, Pritchett e R odrik (2004), ao analisar períodos de rápida aceleração no crescimento econômico (i.e, crescimento sustentado por pelo menos oito anos) desde os anos 1950, concluíram que tais acelerações tendem a ser correlacionadas a investimento e comércio, e também com depreciações na taxa de câmbio real. A principal conclusão do estudo, contudo, é que as acelerações de crescimento em boa medida não são prognosticáveis: na maioria dos casos elas não são relacionadas a determinantes padrões, e tampouco estão relacionadas a reformas econômicas de cunho liberalizantes. ${ }^{21}$

De fato, um dos fatores chaves do chamado catching-up é um país saber extrair vantagens das oportunidades criadas pelo momento histórico em que se vive. Um dos exemplos mais recentes é o caso da Coréia do Sul, que soube tirar proveito da situação geopolítica do pós-guerra e de sua proximidade com o Japão. ${ }^{22}$ Países asiáticos - que se industrializaram principalmente a partir do pós2a Guerra M undial - utilizaram-se inicialmente de uma estratégia de substituição de importações, mas implantaram ao mesmo tempo (e crescentemente) uma estratégia baseada na exportação de bens manufaturados, adotando para tanto um protecionismo seletivo, uma política de câmbio ativo e de subsídios, além de fortes investimentos na formação de capital humano, no contexto de uma estratégia nacional fortemente intervencionista.

Em particular, o desenvolvimento de um país depende da geração de capacidade própria de inovação e de financiamento. Sem dúvida, o Brasil realizou com sucesso - seu processo de industrialização pesada, a partir do Plano de M etas, procurando imitar o padrão de industrialização da 2a R evolução Industrial, o que foi possível nos anos 1950 e 1960 em função do processo de internacionalização do capital produtivo, via expansão das empresas transnacionais dos EUA e da Europa. A industrialização, contudo, foi realizada sem um esforço de criação de capacidade própria de inovação e financiamento. Educação básica nunca foi prioridade no Brasil, pelo menos até recentemente; tampouco se criou um sistema nacional de inovação capaz de propiciar sinergias e interface entre universidades, centros de pesquisa e o setor produtivo; o protecionismo, como já assinalado, foi indiscriminado e sem prazo para terminar; e o financiamento, particularmente o financiamento de longo prazo, foi o "calcanhar de Aquiles" do processo de industrialização brasileiro, utilizando-se para tanto a via do financiamento infla-

\footnotetext{
${ }^{21}$ H ausmann, Pritchett e R odrik (2004) usam, como variáveis explicativas da aceleração do crescimento, variáveis relacionadas a choques externos, mudanças políticas e reforma econômica, e observam que: "os determinantes dos episódios de crescimento (...) são pobremente explicados por nossas variáveis explicativas" (p. 21) , para então concluir que "acelerações de crescimento são causadas predominantemente por mudanças idiossincráticas e freqüentemente de pequena escala" (p. 22).

${ }^{22}$ Ver, entre outros, Evans (1987).
} 
cionário, do endividamento externo, ou mesmo do auto-financiamento das empresas. 0 Brasil pôde ainda assim crescer a uma taxa média de 7,0\% ao ano até o final dos anos 1970, aproveitando-se de conjunturas externas favoráveis, como se fosse uma "procissão de milagres", para usar uma conhecida expressão do sociólogo Sérgio Buarque de Holanda. Contudo, desde os anos 1980, os constrangimentos macroeconômicos impedem que a economia brasileira possa crescer de forma sustentada, seja em função da aceleração inflacionária (até 1994), seja em função da vulnerabilidade a choques cambiais.

Tampouco tem-se conseguido mais adotar uma estratégia de desenvolvimento de longo prazo para o país. Este requer uma boa combinação de políticas específicas (política educacional, política industrial, política científico-tecnológica, etc.) e políticas macroeconômicas consistentes. Por exemplo, o sucesso de uma política industrial depende, em parte, de uma boa articulação com as políticas macroeconômicas. U ma política econômica persistentemente contracionista com juros reais el evados e política fiscal de contenção de gastos - pode inviabilizar uma política industrial pelo simples fato de que não cria um ambiente propício que estimule os empresários a investir.

A política econômica, na perspectiva novo-desenvolvimentista aqui proposta, relaciona-se à adoção de um conjunto de medidas que visa a aumentar o nível de demanda agregada, de modo a criar um ambiente estável que estimule os empresários a realizar novos investimentos - uma vez que os níveis de emprego e utilização da capacidade produtiva dependem, em boa medida, dos determinantes da demanda agregada, principalmente da decisão de investimento dos empresários. Em outras palavras, a política econômica deve procurar afetar o investimento privado global, criando um ambiente seguro que estimule escolhas mais arriscadas - mas que rendam lucros e geram empregos - no lugar da simples acumulação de ativos líquidos - isto é, a boa política é aquela que induz os agentes a investirem em ativos de capital, dando origem a investimento novo (Carvalho, 1999).

Contudo, o objetivo da política econômica deve ser amplo; ela deve estar voltada para a estabilidade macroeconômica, um conceito mais amplo do que 0 de mera estabilidade de preços, ou seja, deve procurar também reduzir as incertezas relativas à demanda futura que são inerentes aos negócios na economia. Estabilidade de preços e aumento do produto e emprego devem ser compatíveis dentro dessa visão e, para tanto, o governo deve fazer uso de um instrumental de política econômica com objetivos múltiplos - e não somente utilizar a política monetária voltada exclusivamente para o controle da inflação. A perspectiva novo-desenvolvimentista sustenta que para se atingir os objetivos múltiplos de política - como crescimento econômico e estabilidade de preços - é necessária uma maior coordenação de políticas (fiscal, monetária e cambial): devem-se avaliar os impactos conjuntos da adoção das políticas sobre os objetivos como um todo. Assim, a coordenação de políticas é fundamental para se atingir a estabilidade macroeconômica.

Igualmente importante é manter uma taxa de câmbio competitiva (ou seja, desvalorizada), como mostra a experiência de vários países que tiveram cresci- 
mento acelerado no pós-guerra, de modo a garantir condições de sustentabilidade do balanço de pagamentos através da geração de superávits crescentes em conta corrente (com conseqüente aumento nas reservas internacionais) e arrefecer a contratação de empréstimos externos (reduzindo, assim, a vulnerabilidade externa do país). Como será visto adiante, deve-se buscar também adotar medidas que diminuam a volatilidade da taxa de câmbio.

\section{ESTADO FORTE, MERCADO FORTE E A REDUÇÃO DA VULNERABILIDADE EXTERNA}

A economia brasileira - assim como diversas outras economias de pequeno e médio portes - tem enfrentado nos últimos anos diversas crises. 0 mercado financeiro, nacional e internacional - , e não o mercado produtor e consumidor de bens e serviços - tem sido o responsável pela constituição desses contextos de adversidade. A rotina tem sido a seguinte: primeiro, impulsionados por motivos de ordem econômico-financeira ou até mesmo de ordem política, financistas brasileiros e estrangeiros decidem retirar do país os recursos que administram; segundo, durante a fuga dos captais, a taxa de câmbio se eleva bruscamente; terceiro, o Banco Central do Brasil reage vendendo reservas e/ou títulos indexados à variação do dólar e à taxa Selic e, simultaneamente, aumenta a taxa de juros básica da economia - no que, sob essas circunstâncias, resulta em uma enorme transferência de recursos da sociedade para o setor financeiro. Por último, como as medidas adotadas nunca são capazes de conter a fuga de capitais e a instabilidade cambial, o país recorre ao FM I, tomando empréstimos, já que suas reservas se esvaíram - e, ademais, aceita com tranqüilidade as condicionalidades impostas pelo Fundo. Entre estas se destacam a geração de mega-superávits primários fiscais, a manutenção de taxas elevadas de juros para conter a inflação e reformas de cunho estrutural. É assim quea economia brasileira tem operado nos últimos anos.

Uma nova crise sempre está rondando a economia brasileira - em função da existência de uma conta de capital totalmente aberta ao movimento dos fluxos de capitais. 0 s motivos que podem fazer eclodir uma nova crise são os mais variados: a elevação da taxa de juros nos Estados Unidos, os efeitos de um possível ajuste da economia americana em função do seu enorme déficit em conta corrente, a possibilidade de redução da velocidade de crescimento da $\mathrm{China}^{23}$ ou a

\footnotetext{
${ }^{23}$ A diminuição do ritmo de crescimento da economia chinesa pode implicar a redução do preço das commodities já que é grande importadora mundial neste segmento. 0 Brasil tem obtido bons resultados comerciais com o exterior porque tem conseguido exportar quantidades consideráveis de commodities que estão com seus preços em patamares elevados. Logo, uma redução do ritmo de crescimento da China pode implicar uma maior dificuldade para o Brasil obter receitas de exportação, isto é, receitas em dólares, o que reduziria os seus saldos comerciais com o exterior.
} 
elevação do preço internacional do petróleo. N o passado recente, foram as crises do M éxico, da Rússia, dos países asiáticos, da Argentina, os atentados de 11 de setembro de 2001, as fraudes Enron/A nthur-A ndersen, as desconfianças relativas ao candidato líder das pesquisas em 2002 etc., que motivaram as fugas de capitais, as crises cambiais, as perdas de reservas, a elevações da taxa de juros e a manutenção de uma taxa de crescimento medíocre. Sempre que a economia inicia um movimento de go, as crises cambiais acabam por provocar um movimento de stop. Como o Brasil passou por diversas crises nos últimos anos, a economia esteve muito mais para stop do que para go, alternando pequenos ciclos de crescimento com desaceleração econômica.

É por isso que um projeto novo-desenvolvimentista deve buscar formas de blindar a conta de capital do balanço de pagamentos, isto é, fórmulas devem ser buscadas com o objetivo de reduzir os efeitos desses choques internos e/ou externos sobre a taxa de câmbio. A final, vários estudos têm mostrado os efeitos nefastos que a excessiva volatilidade da taxa de câmbio, em países em desenvolvimento, tem sobre decisões de investimento, inflação, dívida pública, etc. ${ }^{24} \mathrm{~N}$ este sentido, deve-se buscar adotar medidas que reduzam a volatilidade excessiva da taxa de câmbio e, ao mesmo tempo, mantenham uma taxa de câmbio atraente para fomentar as exportações. ${ }^{25} \mathrm{H}$ á experiências relevantes na história da economia mundial contemporânea que podem ser consideradas lições porque podem indicar algumas linhas gerais de uma estratégia de blindagem para a economia brasileira - são linhas alternativas àquel as sugeridas pel os economistas monetaristas neoliberais, pelos analistas ligados aos sistemas financeiros nacional e internacional e pelo Fundo M onetário Internacional.

Essa é uma das diferenças fundamentais entre o velho e novo desenvolvimentismo. Enquanto o primeiro focava suas políticas defensivas na balança comercial, procurando tornar a economia menos dependente da exportação de produtos primários, uma vez que a economia brasileira transitava de uma economia agro-exportadora para uma economia industrial; o segundo - neste particular - está basicamente preocupado em estabelecer critérios de controle da conta de capitais para que o país possa ter trajetórias de crescimentos não abortadas e possa constituir políticas autônomas rumo ao pleno emprego e à equidade social. ${ }^{26}$ 0 protecionismo moderno deve ser 0 da conta de capitais - as transações comerciais devem ser liberalizadas, embora esta abertura deva ser feita de uma for-

\footnotetext{
${ }^{24}$ Ver, entre, outros, Guérin e Lahrèche-Révil (2003) e IM F (2003).

${ }^{25}$ Como a experiência recente de alguns países asiáticos, como China, Coréia do Sul e M alásia, que mostra que a expansão das exportações líquidas tem como importante corolário a formação de reservas cambiais que serve tanto como um colchão de reservas contra especulação cambial quanto para intervenção da autoridade econômica na determinação da taxa de câmbio, quando necessário.

${ }^{26}$ Ver, neste particular, Paula e O reiro (2003) e Carvalho e Sicsú (2004).
} 
ma inteligente, cautelosa e negociada para que reciprocidades que interessem às exportações brasileiras sejam conquistadas. ${ }^{27}$

\section{ESTRATÉGIA NACIONAL, NACION ALISM O E DESEN VOLVIMENTISM O}

U ma das características do processo de industrialização latino-americano incluindo o Brasil - é a assimetria entre um elevado componente de imitação (fase prévia de aprendizagem) e um componente marginal de inovação econômico-social. A demais, nenhum país da região logrou simultaneamente crescimento e eqüidade social. Economias bem-sucedidas em termos de crescimento e eqüidade compartilham uma característica básica, que é a incorporação do progresso técnico e elevação da produtividade. N este contexto, em função das insuficiências no âmbito da eqüidade e da baixa incorporação do progresso técnico em setores-chaves da indústria, o crescimento econômico e a competitividade apresentaram um comportamento claramente espasmódico na A mérica Latina. ${ }^{28}$

A competitividade do setor industrial contribui positivamente para o crescimento econômico, já que o comércio internacional de manufaturas é o que mais se expande no comércio mundial, e, ao mesmo tempo, o crescimento contribui para estimular a introdução de progresso técnico e, conseqüentemente, aprimorar a competitividade. Embora a capacidade dos países de se inserir de forma mais efetiva nos mercados internacionais dependa, em parte, de sua capacidade de acompanhar as tendências tecnológicas internacionais, para muitos países que não estão na fronteira tecnológica, os retornos associados com a facilidade de transferência da tecnologia podem ser maiores do que os retornos de desenvolverem de forma pioneira pesquisa e desenvolvimento. Por isso, políticas públicas que facilitem a transferência da tecnologia - assim como a sua absorção pelo aparelho produtivo - são cruciais para o desenvolvimento. ${ }^{29}$

Portanto, nos países latino-americanos, como o Brasil, é fundamental a realização de uma transformação produtiva que resulte na el evação da produtividade da mão-de-obra que dê sustentação a uma competitividade internacional autêntica apoiada na incorporação de progresso técnico e em práticas gerenciais inovadoras. Para tanto, uma política abrangente deve ser adotada, incluindo o fortalecimento da base empresarial do país, a adoção de uma política industrial voltada para a melhoria da competitividade das exportações de maior valor agregado, o desenvolvimento de uma infra-estrutura voltada para a competitividade sistêmica (incluindo o desenvolvimento de um sistema nacional de inovação), me-

\footnotetext{
${ }^{27}$ Cabe ser ressaltado que, neste último aspecto, o M inistério das R elações Exteriores do atual G overno tem dado alguns exemplos de que é possível assumir uma postura em defesa dos interesses nacionais sem criar turbulências desnecessárias.

${ }^{28}$ Cf Fanjnzylber (1989).

${ }^{29}$ Ver, a respeito, Stiglitz (1999).
} 
Ihorias do nível de qualificação da mão-de-obra, etc. A aprendizagem tecnológica e o fortalecimento da competitividade internacional requerem instituições públicas dotadas de capacidade de articulação dos diversos agentes produtivos, laborais, educativos, de pesquisa e de financiamento. Como já assinalado, o Estado necessário para impulsionar uma transformação produtiva dessa natureza é diferente daquele que fomentou a industrialização precedente.

D eve-se assinalar que nenhum país se desenvolveu ou se mantém desenvolvido - tal como os Estados Unidos, a França ou a Alemanha - ou entra em rota de desenvolvimento - tais como alguns países asiáticos - sem um projeto claro que expressasse 0 sentimento de nação. 0 sentimento nacionalista reforça um projeto de desenvolvimento, particularmente no mundo atual em que as finanças e os negócios estão, em grande parte do mundo, integrados. $\mathrm{N}$ acionalismo significa tão somente um conjunto de atitudes de governos e cidadãos com 0 objetivo de defender o capital e o trabal ho do seu país no mundo em que empresas competem por novos mercados e em que capitais financei ros buscam, além de suas fronteiras, aumentar a sua rentabilidade exigindo menores riscos - ou seja, um projeto de desenvolvimento que atenda os interesses nacionais, e que permita uma inserção soberana do país na economia internacional.

A história mundial mostra também que não há capitalismo forte sem um empresariado nacional forte. Em outras palavras, sem a consolidação de um "núcleo endógeno" de desenvolvimento - constituído de um empresariado nacional forte e competitivo - o desenvolvimento torna-se frágil, pois não se criam grupos empresariais capazes de participar em igualdade de condições do pesado jogo de competição internacional de comércio e investimentos.

O s monetaristas neoliberais usam o termo nacionalismo em tom desabonador - associando-o, no plano político, ao autoritarismo e, no plano econômico, a um protecionismo primitivo - que objetivaria um isolamento que aceitaria com tranqüilidade 0 atraso e a falta de competitividade. Pregam a integração comercial cega, a liberalização financeira plena e até mesmo o fim da autonomia de governos para decidir onde realizar seus gastos. A idéia que eles têm vendido ao mundo não desenvolvido é que: quando um país se integra à globalização sem restrições, ele passa a se beneficiar tanto da intensificação dos fluxos comerciais quanto do aumento de poupança externa para dar suporte ao crescimento. A estratégia de crescimento com endividamento externo para os países em desenvolvimento tem se revelado, no entanto, uma tragédia, pois ciclos de crescimento são seguidos por ciclos de forte desaceleração, resultado dos impactos das mudanças nas condições do mercado financeiro internacional. ${ }^{30}$

Este pensamento monetarista neoliberal globalizante e, portanto, anti-nacionalista, é basicamente formulado por intelectuais e economistas americanos, 0 que não deixa de ser surpreendente considerando que os EUA foram o berço da

${ }^{30}$ Para uma avaliação crítica da estratégia de "crescimento com endividamento externo", ver BresserPereira e N akano (2004). 
ideologia de proteção a indústria infante e um dos países mais protecionistas do mundo até a 2 a Guerra M undial. ${ }^{31}$ Contudo, foi lá nos Estados Unidos que na disputa eleitoral entre John Kerry e Gorge W.Bush, cada dia, um dos candidatos tentava demonstrar ao el eitorado quem era o mais capaz de defender o capital e o trabalho americanos. Disputavam abertamente quem era o mais nacionalista. E isso é inegável, americanos pregam a integração globalizante para os não desenvolvidos, mas são provavelmente um dos governos e um dos povos mais nacionalistas do planeta. São tão nacionalistas que ousam (e são capazes de) convencer as elites intelectuais e governantes dos países não desenvolvidos de que devem abrir mão de projetos nacionais, próprios, e que devem se integrar ao projeto americano de "bem-estar" mundial.

A ideologia da globalização sustenta que a interdependência das nações se aprofundou em tal grau que os Estados nacionais se tornaram impotentes e mesmo irrelevantes. 0 projeto globalizante é um projeto de desintegração nacional e de enfraquecimento intel ectual, econômico e cultural de todos os segmentos de uma sociedade. 0 s mercados de sociedades globalizadas são, portanto, tragados com facilidade pelos mercados internacionais. Uma alternativa novo-desenvolvimentista visa colocar os mercados nacionais na condição de serem ligados aos mercados internacionais, de tal forma que esta ligação possa trazer sempre muito mais ganhos do que perdas, em termos de geração de conhecimentos, novos empregos, crescimento e bem-estar social. Trata-se de implementar uma estratégia que permita ao país uma inserção soberana no processo de globalização em curso no mundo. Em que pese a maior interdependência entre as nações, Estados são estratégicos como instrumento de ação coletiva que as nações dispõem para serem competitivas internacionalmente.

\section{NÃO É POSSÍVEL ATINGIR O OBJETIVO DA REDUÇÃO DA DESIGUALDADE SOCIAL SEM CRESCIMENTO A TAXASELEVADASE CONTINUADAS}

Um dos debates acalorados dentro da Ciência Econômica diz respeito aos mecanismos para assegurar uma melhor distribuição da renda e da riqueza. Este debate coloca sempre em oposição aqueles economistas que entendem que a qualificação da mão-de-obra, reformas na legislação trabal hista e/ou políticas sociais são os instrumentos mais eficientes para se alcançar um melhor perfil distributivo; e, de outro lado, um outro grupo de economistas que entende ser o crescimento econômico, a taxas elevadas e permanentes, o que vai assegurar uma meIhora no perfil distributivo. A mbos os lados trazem contribuições importantes ao debate.

${ }^{31}$ Cf. Chang (2004, cap. 2). 
A perspectiva aqui defendida é um meio termo entre as duas posições acima, pois entende-se que somente o crescimento econômico a taxas elevadas e continuadas pode minorar o problema da desigualdade na economia brasileira. ${ }^{32}$ $M$ as esta é apenas uma condição necessária porque gera empregos e arrecadação tributária que pode ser utilizada na implementação de programas sociais universalizastes. É condição necessária mas não suficiente porque políticas sociais e educacionais - entendidas como instrumentos para a inclusão econômica formal de segmentos da população deseducados que possuem baixa produtividade no trabalho e que recebem, em conseqüência, baixos salários - são elementos também centrais no enfrentamento da questão das exageradas desigualdades presentes no país. Todavia, qualificação sem crescimento produzirá, por exemplo, uma gama de trabalhadores bem-educados subempregados ou desempregados.

Políticas sociais - como políticas de renda mínima - implementadas em um contexto de crescimento baixo podem se revelar limitadíssimas, ou seja, incapazes de garantir uma maior igualdade porque transformam os seus beneficiários em dependentes de "migal has" em um contexto em que oportunidades de melhora efetiva de renda inexistem porque oportunidades de trabalho estão restritas. Tais políticas implementadas em economias estagnadas são soluções emergenciais necessárias, mas estão longe de ser soluções permanentes. Há talvez um risco mais grave, podem se transformar em meras políticas assistencialistas, com todos os riscos políticos inerentes a estes processos. Por fim, programas de qualificação e capacitação de mão de obra são fundamentais no atual estágio de desenvolvimento tecnológico, mas não se deve ignorar os problemas do lado da demanda por trabalho, que depende, por sua vez, crucialmente da demanda efetiva da economia: ${ }^{33}$ políticas ativas de emprego só podem cumprir plenamente as funções para os quais foram concebidas quando existe demanda pelas atividades que promovem.

\section{REFERÊNCIAS BIBLIOGRÁFICAS:}

BIELCH OWSKY, R., (1988). Pensamento E conômico Brasileiro: o ciclo ideológico do desenvolvimentismo. Rio de Janeiro: IPEA.

BIELCH O WSKY, R., org. (2000). Cinqüenta Anos de Pensamento na CEPAL. Rio de Janeiro: Record. BRESSER -PEREIRA, L.C. (2003). D esenvolvimento e Crise no Brasil. 5ạ. Edição. São Paulo: Editora 34.

\footnotetext{
${ }_{32}$ Salm (2005, p. 200), ao analisar o crescimento do produto e de renda no Brasil entre 1960 e 1980, conclui: "não fosse o crescimento proporcionado pelos investimentos que introduziram os estágios mais avançados da indústria na época, o desemprego e a informalidade já teriam eclodido bem antes da crise da dívida. Q uando examinamos os números brasileiros do período, impressiona o dinamismo da geração de empregos pelos novos setores".

${ }^{33}$ De fato as propostas de cunho liberal, voltadas exclusivamente para os problemas do lado da oferta, parte da premissa que as oportunidades de trabalho sempre existem, mas que não são aproveitadas por carências no âmbito dos fatores de produção, como falta de qualificação da mão-de-obra e de acesso ao crédito.
} 
BRESSER-PEREIRA, L.C. (2004a). "N ovo-desenvolvimentismo". Folha de São Paulo/ Caderno Dinheiro, 19/09/2004.

BRESSER-PEREIRA, L.C. (2004b). D emocracy and Public M anagement R eform: building the Republican state. Oxford: Oxford University Press.

BRESSER-PEREIRA, L.C. e N AKAN O, Y. (2004). "Crescimento econômico com poupança externa?" In Ferrari-Filho, F. e Paula, L.F. (org.). G lobalização Financeira: ensaios de macroeconomia aberta. Petrópolis: Vozes.

CARVALH O, F.C. (1999). "Políticas econômicas para economias monetárias" . In Lima, G.T., Sicsú, J. e Paula, L.F. (org.). M acroeconomia M oderna: K eynes e a economia contemporânea. Rio de Janeiro: Campus.

CARVALH O, F.C. e SICSÚ, J. (2004). “Controvérsias recentes sobre controles de capitais". Revista de Economia Política, vol. 24, n. 2, pp. 163-184, abril/junho.

CEPAL (1990). Transformacion Productiva com Equidad. Santiago: CEPAL.

CHAN G, H -J. (2004). Chutando a Escada: a estratégia de desenvolvimento em perspectiva histórica. São Paulo: Editora UNESP.

D O RN BUSCH, R. (1998). "Capital controls: an idea whose time is past". In Essays in International Finance n. 207, Princeton University, M ay.

DAVIDSO N , P. (1994). Post Keynesian M acroeconomic Theory. Cheltenham: Edward Elgar.

EVAN S, P. (1987). "Class, state and dependence in East Á sia: lessons for latin americanists" . In DEY O , F. (org.). The Political E conomy of the N ew A sian Industrialism. Ithaca: Cornell University Press.

FAN J N ZY LBER, F. (1989). Industrializacion en A merica L atina: de la "caja negra" al "casillero vacio". Santiago del Chile: CEPAL.

FISCHER, S. (1998). "Capital-account liberalization and the role of the IM F". In Essays in International Finance n. 207, Princeton University, M ay.

GUÉRIN , J.-L. e LAHRĖCHE-RÉVIL, A. (2003). Exchange rate volatility and investment, mimeo.

H AUSM AN N, R., PRITCHETT, L. eRODRIK, D. (2004). "Growth accelerations". N BER Working Paper Series no. 10566, June.

HAYEK, F. (1984). O Caminho da Servidão. Rio de Janeiro: Instituto Liberal.

IM F (2003). "Public debt in emerging markets: is it too high?" In World Economic 0 utlook, chapter III. Washington: IM F, September.

KEY N ES, J.M . (1984), “O fim do laissez-faire”. In: Szmrecsányi, T. (org.). John M aynard Keynes. São Paulo: Ática.

.(1986). The G eneral Theory of Employment, Interest and M oney. London: M acM illan.

PAULA, L.F., O REIRO, J.L. e SILVA, G.J.C. (2003). "Fluxos e controle de capitais no Brasil: avaliação e proposta de política". In Sicsú, J., O reiro, J.L. e Paula, L.F. (org.), A genda Brasil: políticas para o crescimento com estabilidade de preços. Barueri: M anole.

PO LAN Y I, K. (1980). A G rande Transformação: as origens da nossa época. Rio de Janeiro: Campus.

SALM , C. (2005). "Estagnação econômica, desemprego e exclusão social”. In Sicsú et al (org.), N ovo-desenvolvimentismo, op.cit.

SERRA. J. (1982). "Ciclos e mudanças estruturais na economia brasileira do pós-guerra". In Belluzzo, L.G e Coutinho, R. (org.), D esenvolvimento Capitalista no Brasil: ensaios sobre a crise. São Paulo: Brasiliense.

SICSÚ, J., PAULA, L.F. e M ICH EL, R., org. (2005). N ovo-D esenvolvimentismo: um projeto nacional de crescimento com eqüidade social. Barueri/R io de Janeiro: M anole/Fundação Konrad Adenauer.

SM ITH , A . (1983). A Riqueza das N ações. São Paulo: A bril Cultural.

SN OWDON, G., VANE, H. eWYN ARCZYK, P. (1994). A M odern G uide to M acroeconomics. Cheltenham: Edward Elgar.

STIGLITZ, J. (1999). "M ore instruments and broader goals: moving toward the Post-Washington consensus". Revista de Economia Política, v.19, n.1, pp. 94-120, jan./mar

SUZIGAN , W. (1988). "Estado e industrialização no Brasil". Revista de Economia Política, v. 8, n. 4, pp. 5-16, out./dez.

WILLIAM SO N, J. (1990). "W hat Washington means by policy reform". In Williamson, J. (org.). Latin A merica A djustment: how much has happened? Washington: Institute for International Economics. 